\title{
Evolution of an ecological trait in parthenogenetic Sitobion aphids
}

\author{
PAUL SUNNUCKS*, DARREN CHISHOLM, EREN TURAK† \& DINAH F. HALES \\ School of Biological Sciences, Macquarie University, NSW 2109, Australia
}

\begin{abstract}
The aim of this study was to test whether host plant responses of Sitobion aphids have evolved under parthenogenesis and to examine the relationship between genetic and phenotypical similarity. There are four known chromosomal races of Australian Sitobion miscanthi living on grasses. Three races evolved from a recent common ancestor by mutation and chromosomal rearrangement alone. Australian $S$. miscanthi reproduce entirely by parthenogenesis, as does the close congeneric $S$. near fragariae. Mean relative growth rate (MRGR) was investigated in laboratory-raised representative aphid clones of four races of $S$. miscanthi, and also $S$. near fragariae (i.e. five aphid 'forms') on three host plants, with 15 replicate aphids per clone. There were significant differences in MRGR; most variance was associated with differences among forms, some among clones within forms and very little with aphids within clones. Developmental time and adult weight both contributed to the differences in MRGR. There was a significant interaction for clone(nested within forms) $\times$ host for all three dependent variables. No one clone performed significantly better over all hosts than other clones of its form (clonal MRGRs on the three hosts were negatively correlated). Nearly all clones performed best on barley (which was the only 'familiar' host, in that previous generations had been raised on it), next best on cocksfoot and worst on rye. MRGR was found to be under genetic control. The data show that monophyletic parthenogenetic aphids can rapidly evolve substantial differences in host relations and suggest a possible association of chromosomal rearrangements with MRGR.
\end{abstract}

Keywords: genetic variation, host plant, microsatellite, mean relative growth rate, parthenogenesis, Sitobion aphids.

\section{Introduction}

Evolution in parthenogens

The rarity of parthenogenesis requires explanation, given its twofold advantage over sex in not producing males (Maynard Smith, 1978). A major type of hypothesis to resolve this paradox is that short- and long-term evolutionary responsiveness of parthenogenetic organisms could be limited by the accumulation of deleterious mutations or low genotypical variation (Hughes, 1989; Lynch et al., 1993). Nonetheless, there are theoretical and empirical challenges to the idea that parthenogenesis is an

\footnotetext{
*Correspondence. E-mail: psunnuck@rna.bio.mq.edu.au

$\dagger$ Present address: Environmental Protection Agency, Bankstown Civic Tower, 66-72 Rickard Road, Locked Bag 1502, NSW 2200, Australia.
}

'evolutionary dead end' (Judson \& Normark, 1996; Simon et al., 1996a,b; Fagerström et al., 1998). Most importantly, clonal organisms may persist and diversify over evolutionary time (Judson \& Normark, 1996).

Compared with the wealth of theory, there is a dearth of experimental tests of hypotheses about the evolution and maintenance of sex and parthenogenesis (see Sunnucks et al., 1997a). An important area of research is the rate at which parthenogenetic reproduction can generate useful functional variation. Although studies of genetic variation in parthenogenetic organisms have been reasonably plentiful, investigations of the functional outcomes of genetic variability have been rare. More importantly, there are very few published studies of functional variation in multicellular parthenogens known to have evolved from a common ancestor under 
parthenogenesis. In most detailed studies of ecological trait variation in parthenogens, it is likely that intertaxon hybridization or polyploidy was involved in the transition to parthenogenesis, or the relationships among taxa are unknown and, thus, the evolutionary timescale of the attribute variation cannot be determined (e.g. most or all of the examples in Lynch, 1984; Müller \& Seitz, 1995; Sunnucks et al., 1997b; Turak et al., 1998). Experimental studies have shown that trait evolution can occur rapidly in monophyletic parthenogenetic lineages (Lynch, 1985; Toline \& Lynch, 1994), but studies of free-living organisms of known genetic relationships are most uncommon. The present research represents such a study.

\section{Genetics and ecology of the model species - Sitobion aphids}

As part of a programme researching the role of mode of reproduction in evolution (references below), we are investigating the genetics and ecology of two species of sympatric parthenogenetic Sitobion aphids on grasses and cereals in Australia: $S$. miscanthi and an undetermined species $S$. near fragariae (M. Carver and V. Eastop, pers. comm.). Sitobion miscanthi has an Asia-Pacific distribution. There are four known chromosomal races of $S$. miscanthi in Australia, with chromosome numbers of $2 n=17,18,20$ and 21 (Hales et al., 1990; Sunnucks et al., 1996). Genetic data indicate that races $2 n=17,2 n=20$ and $2 n=21$ have evolved from a recent common ancestor $(2 n=18)$ by mutation and chromosomal rearrangement alone, most probably since colonizing Australia (Sunnucks et al., 1996).

In the present study, host relations of all the known forms of Australian grass/cereal Sitobion, which can be arranged in a hierarchy of genetic relatedness (Sunnucks \& Hales, 1996; Sunnucks et al., 1996), were investigated. Sitobion near fragariae is a clear outgroup which differs from $S$. miscanthi by $3.4 \%$ of a mitochondrial DNA gene and by $1 \%$ in a small nuclear intron of the gene elongation factor $1 \alpha$ (there was little and no sequence variation, respectively, for these markers within species). Within S. miscanthi, $2 n=18$ shares none of its microsatellite alleles with Australian conspecifics. The remaining three forms are a monophyletic group, in which $2 n=17$ is a sister group to $2 n=20 / 21$ (sharing $63 \%$ of microsatellite alleles with them), whereas $2 n=20$ and $2 n=21$ are very closely related (they share $88 \%$ of microsatellite alleles at four loci) but also differ, in that $2 n=21$ has experienced an $\mathrm{X}$ chromosome fission.
Race $2 n=17$ has an autosomal fusion relative to the $2 n=18$ ancestral karyotype (Hales et al., 1990; Sunnucks et al., 1996).

Sitobion miscanthi and $S$. near fragariae have been collected from flowers of a wide range of grasses and sedges in Australia. The distributions of the races of $S$. miscanthi are heterogeneous. For example, about $80 \%$ of $S$. miscanthi in the state of Victoria (VIC) are race $2 n=21$, but this form is almost absent from the Sydney region in New South Wales (NSW) (Sunnucks et al., 1996). The aphid forms may have different seasonality (Hales et al., 1990), and longer term changes in abundance may occur: S. miscanthi $2 n=20$ made up only $3 \%$ of clones collected throughout the year in the Sydney region before 1990 (Hales et al., 1990) but, since 1993, has comprised approximately $30 \%$ of samples (Sunnucks et al., 1996). In addition, a degree of host specialization among $S$. miscanthi has been detected in field-collected samples (T. Sloane, P. Sunnucks and D. F. Hales, unpubl. obs.).

We use the word 'form' to describe races of $S$. miscanthi, plus $S$. near fragariae. All forms are distinguishable by genetic techniques, and the genetic relatedness among them has been estimated (above). Genetic variation within chromosomal races is very slight compared with that among. Genetic data strongly suggest that reproduction is by parthenogenesis alone, because widespread and extensive sampling has failed to detect recombinant (sexual) genotypes in the field (Sunnucks et al., 1996). Nonetheless, sexual morphs of Australian $S$. miscanthi and $S$. near fragariae can be induced in the laboratory by exposure to day length and temperature regimes mimicking northern hemisphere autumn (e.g. Wilson et al., 1997).

Parthenogenesis in aphids is considered to be apomictic (i.e. mitotic, review in Hales et al., 1997), so that, except for mutations, offspring should be identical to their mother. However, it is possible that some exchange occurs between the large $\mathrm{X}$ chromosomes during apomictic reproduction in at least some aphids (Blackman \& Hales, 1986). Such a process of 'cryptic recombination' might speed up adaptation by the generation of new combinations of genetic variation. So far, there is no evidence from field-collected Sitobion that this occurs: $121 \mathrm{~S}$. near fragariae showed no segregation of their alleles at heterozygous X-linked microsatellite locus Sm11 (Sunnucks et al., 1996; Wilson et al., 1997), but segregation would have been expected if X recombination were relatively common (Blackman, 1979).

Host plant and temperature are widely regarded as overwhelmingly the most important extrinsic 
factors in aphid ecology (Hales et al., 1997). Host plant responses in experimental conditions are measurably variable among clones of Sitobion avenae (Caillaud et al. 1995; De Barro et al., 1995a,b), and genotypical host specialization is seen in the field (Sunnucks et al., 1997a). There is evidence for natural ecological differences between the sympatric forms of Sitobion on grasses in Australia. Geographical and temporal distributions are patterned in the face of ready dispersal (Sunnucks $e t$ al., 1996), there are different responses to temperature (Turak et al., 1998) and different rates of colonization of different hosts occur in the wild ( $\mathrm{T}$. Sloane, P. Sunnucks and D. F. Hales, unpubl. obs.). For these reasons, the responses of Australian Sitobion aphids to different host plants under controlled conditions have been characterized. In parallel research, temperature responses have been investigated (Turak et al., 1998). Here, experiments on responses to host plants by Sitobion aphids are reported. Evidence that lineages that diverged under apomixis (with no detected genetic recombination) have developed differences in their responses to host plants is presented.

\section{Materials and methods}

Aphids

Eleven Sitobion clones (lineages derived from single field-caught parthenogenetic females), encompassing all known Australian chromosome variants, were investigated (Sunnucks et al., 1996) (Table 1). Only one replicate of form $2 n=21$ has been used because, when the experiment was designed, the distinction between $2 n=21$ and $2 n=20$ was unrecognized (accordingly, there are only two replicates of $2 n=20)$. We appreciate that the single $2 n=21$ clone tested may not represent this chromosomal race adequately. Only two clones of $2 n=18$ were available at the time of the experiment.

Dependent variables: mean relative growth rate (MRGR) and its components

Intrinsic rate of increase $\left(r_{\mathrm{m}}\right)$ is time-consuming to measure. However, for aphids including Sitobion, the more easily measured mean relative growth rate (MRGR) is highly positively correlated with $r_{\mathrm{m}}$ over a range of conditions (Turak et al., 1998). MRGR was used in this study, calculated as $[\ln$ (weight at adult ecdysis/weight at birth)]/development time in days and hours. (The same individual aphid is measured at the relevant times.)

\section{Host plants}

The MRGR of each clone of Sitobion was determined on three different host plant seedlings. These were barley (Hordeum vulgare L., var. Clipper) and two commercially available pasture grasses: wimmera rye (Lolium rigidum Gaudin, only one variety known) and cocksfoot (Dactylis glomerata L., var. Currie). Barley was chosen because it is our standard culture plant. Rye and cocksfoot were chosen because Sitobion aphids are commonly found on them in our field collections (Sunnucks et al., 1996), and they are morphologically different plants that grew well in our cultures (out of a selection of grasses tried, also including Paspalum dilatatum Poir.

Table 1 Details of the Sitobion clones used in the current experiments

\begin{tabular}{lcll}
\hline Form & Clone & Collection site & Host plant \\
\hline $\begin{array}{l}\text { S. miscanthi } \\
2 n=17\end{array}$ & $34(21)$ & N. Ryde, Sydney, NSW & Paspalum dilatatum \\
& $67(57)$ & Ipswich, QLD & Unrecorded \\
& 140 & E. Ryde, Sydney, NSW & Sedge \\
$2 n=18$ & $4(26)$ & N. Ryde, Sydney, NSW & Paspalum dilatatum \\
& 80 & N. Ryde, Sydney, NSW & Setaria sp. \\
$2 n=20$ & 99 & Gladesville, Sydney, NSW & Paspalum dilatatum \\
& 106 & N. Ryde, Sydney, NSW & Paspalum urvillei \\
$2 n=21$ & 119 & Canberra, ACT & Paspalum dilatatum \\
$S$. near fragariae & & & $07 / 96$ \\
& $2(64)$ & Adelaide, SA & Cereal \\
& $17(1)$ & Lab. stock from Tasmania & Unrecorded \\
& 124 & Canberra, ACT & Paspalum dilatatum \\
\hline
\end{tabular}

Numbers in brackets indicate the clone number in Hales et al. (1990).

(c) The Genetical Society of Great Britain, Heredity, 81, 638-647. 
and Festuca arundinacea Schreb.). For logistical reasons, all three chosen plants could not be tested simultaneously, so all clones were measured simultaneously, first on rye, then cocksfoot, then barley. Rye plants were used at about 4 weeks after sowing, cocksfoot at 2.5 weeks and barley at 1 week (because rye and cocksfoot were slower to germinate and grow than barley). Each clone was represented by 15 replicate aphids, giving $165(11 \times 15)$ test aphids on individually caged plants for each of the test plant species. Plants were taken at random for assignment to test groups of aphids. To obtain the test generation of aphids, winged adults of each clone were placed on caged barley plants for approximately $4 \mathrm{~h}$, after which time 15 of the newborn aphids produced were weighed (Cahn 25 electrobalance) and placed on individual test plants. After the fourth instar, aphids were observed at $10 \mathrm{~h}$ intervals until ecdysis (to wingless adults) occurred, when they were weighed. Plants were grown and experiments were conducted in controlled temperature cabinets at $20^{\circ} \mathrm{C} \pm 1.5^{\circ} \mathrm{C}$ (Zankel Scientific Equipment), with a light intensity of 380-400 $\mu \mathrm{mol} \mathrm{m}^{-2} \mathrm{~s}^{-1}$, from August to November 1993. Clones had been maintained at $20^{\circ} \mathrm{C}$ on barley seedlings since the date of collection shown in Table 1 (at least four generations, and mostly many more). Occasionally, a newborn aphid placed on a plant would fail to achieve adult ecdysis. These were 4.2\% of the observations on barley, $6.7 \%$ on cocksfoot and $14.5 \%$ on rye. Although the missing data could be a result of nutritional differences among hosts, the differences also seemed to be related to the ease of placing newborn aphids on the plants. As there was no clear relationship between the MRGR of clones on a given host and the number of missing data, these data were not included. Exclusion of these data may tend to underestimate differences in host relations, but the effect should be slight - the worst case resulted in only 12 replicates instead of the planned 15, and there is little variance among extant replicates.

Results of parametric statistics are presented only where the variable fulfilled assumptions of normality of distribution and homoscedasticity, using the Kolmogorov-Smirnov one-sample test and Cochran's C and Bartlett-Box F routines in SPSS (version 6.0). Multifactorial two-way ANOvAs were executed in SUPERANOVA (version 1.11, 1991, Abacus Concepts, Berkeley, CA, U.S.A.), and significance testing followed Underwood (1997). Aphid form is a fixed factor, because all Australian forms known on grasses and cereals were sampled, and we are interested in specific differences. For the contrast between barley and the other plants, host plant can be defined as a fixed factor, because barley is the standard culture plant, and culture plant/not culture plant is of interest and under experimental control (see also De Barro et al., 1995b). In the context of investigating the effect of hosts in general, host plant is a random factor. Thus, ANOvAs were carried out with host as a fixed factor (model I) as well as a random one (mixed model): only the former results are presented in full. Comments are made on the mixed model where the results differ from those of model I. For pairwise testing of comparisons contributing to significant ANOVA results, Fisher's protected least significant difference test (PLSD) was used, as implemented by STATVIEW (version 4.5, 1992, Abacus Concepts). Correction for tablewide significance was by the stepwise Bonferroni procedure (Rice, 1989).

\section{Results}

Differences in MRGR among forms, clones and aphids

There were large differences in MRGR among aphid forms and over host plants (Fig. 1; Table 2). Most variance in MRGR was associated with differences among forms, rather than among clones or within clones (Fig. 1; mean squares are an order of magnitude higher between than within forms for all three hosts, data not shown; and see mean squares in Table 3). In similar analyses, developmental rate and adult weight showed similar patterns to those for MRGR and, thus, both contribute to the differences in MRGR.

Overall, $S$. near fragariae had the highest MRGR (with the MRGRs from all 11 clones arranged in descending order for each host, $S$. near fragariae ranked on average 2.3) and, within $S$. miscanthi, the order was $2 n=17$ (average rank 4.9) $>2 n=21$ (7.6) $>2 n=20(8.3)>2 n=18(10.0)$. The interaction term clone(nested within form) $\times$ host was also significant $(P<0.0001)$. However, the MS associated with this interaction was small compared with that for host and form (Table 2; see also Fig. 1), so we consider it worthwhile to investigate differences among levels of these main effects. Host plant and form were highly significant factors (Table 2).

The finding that MRGR of clones within a form were similar (relative to clones of different forms) did not preclude significant differences being commonly detected among them. When MRGR data from each host plant were analysed separately, there were significant differences among clones of a 


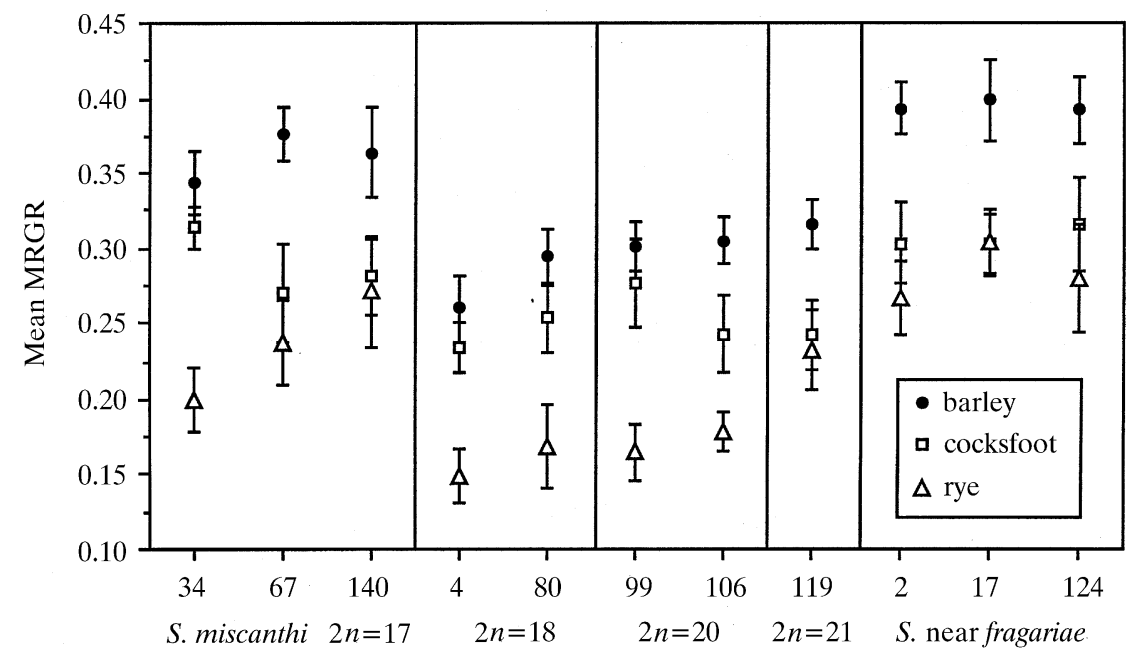

Fig. 1 Plot of mean relative growth rate $(\mathrm{MRGR} \pm \mathrm{SD})$ for 11 Sitobion clones exposed to three different host treatments. form for six out of 12 comparisons (Table 3). Half of the 24 pairwise comparisons between clones of the same form were significant $(P<0.05$, Fisher's PLSD; see Fig. 1), but pairs of clones from different forms were much more different still: $86 \%$ of 147 comparisons were significant $(P<0.05$; see Fig. 1$)$. The comparison of $2 n=17$ with $2 n=20 / 21$ is of special interest, as these diverged by mutation alone, so more detail is presented. All $2 n=17$ clones had significantly higher MRGR than did $2 n=20 / 21$ clones in 23 out of 27 clone-host comparisons. The exceptions were clone $99(2 n=20)$ and two of the three $2 n=17$ clones on cocksfoot $(P>0.5)$ and, on rye, clone $119(2 n=21)$ was not significantly different from clone $67(2 n=17)$ and had a significantly higher MRGR than clone $34 \quad(2 n=17$; $P<0.002$ ).

There was no particular pattern in which host plants induced significant differences among clones within a form (Table 3). Some clones were much more affected by certain host treatments than others (seen in significant clone $($ form $) \times$ host interactions,

Table 2 The results of two-way model I ANOvA investigating the differences in MRGR of Sitobion forms

\begin{tabular}{lrcrl}
\hline Source & d.f. & MS & \multicolumn{1}{c}{$F$} & $P$ \\
\hline Form & 4 & 0.1642 & 40.55 & $<0.0001$ \\
Clone(form) & 6 & 0.0041 & 7.11 & $<0.0001$ \\
Host plant & 2 & 0.4690 & 83.60 & $<0.0001$ \\
Form $\times$ host plant & 8 & 0.0086 & 1.54 & $>0.25$ \\
Clone(form) $\times$ host plant & 12 & 0.0056 & 9.84 & $<0.0001$ \\
Residual & 420 & 0.0006 & & \\
\hline
\end{tabular}

Brackets indicate nested variables.
Table 2, and significant individually for forms $2 n=17,2 n=20$ and Snf, $P<0.03$; data not shown). Some clone $\times$ host interactions were so large that certain clones outperformed members of otherwise 'better performing' forms, significantly so in one case (clone $119>$ clone 34 on rye, above). Clone(form) was only associated with a relatively low $F$-value in the model I analysis (Table 2) and was not significant in the mixed model $(P>0.5)$. Thus, no clone was generally a much better performer than other members of the same form.

\section{Overall effects of host plant treatment on MRGR}

Clones had significantly higher MRGR on host plants in the order barley $>$ cocksfoot $>$ rye, except for three cocksfoot-rye comparisons (Fig. 1; MannWhitney, $P<0.05)$. We note that this mirrors the overall magnitude of failures to achieve adult ecdysis (Materials and methods). Thus, under the conditions of the experiment (movement from barley stock cultures to one of the three hosts) and judged by MRGR data, placement on barley may be defined as the most favourable treatment, on cocksfoot as of intermediate effect, and on rye as the most unfavourable. The MRGR of aphids on host plants was reliably reflected by differences in development time: in all comparisons (except clone 34 cocksfootbarley), development time was shorter on the more favourable host as defined above (Fig. 2a; usually $P<0.001$, data not shown). Patterns of adult weight were less reliably associated with MRGR: in particular, many clones grew to unexpectedly large size on 'unfavourable' rye (Fig. 2b). However, F-ratios for the main effects and interactions in the multivariate 
ANOVAS for each of development time and adult weight were similar, indicating that the magnitude of contribution of these factors to differences in MRGR were approximately the same (data not shown).

\section{Discussion}

Mutation in parthenogens gives rise to potentially selectable phenotypic variation

We have shown significant genetically based differences in MRGR on different host plants among closely related parthenogenetic aphids. Three of the forms $(2 n=17,2 n=20$ and $2 n=21)$ are thought to have diverged from a very recent common ancestor

Table 3 The results of one-way ANOva investigating the differences in MRGR of Sitobion clones within forms

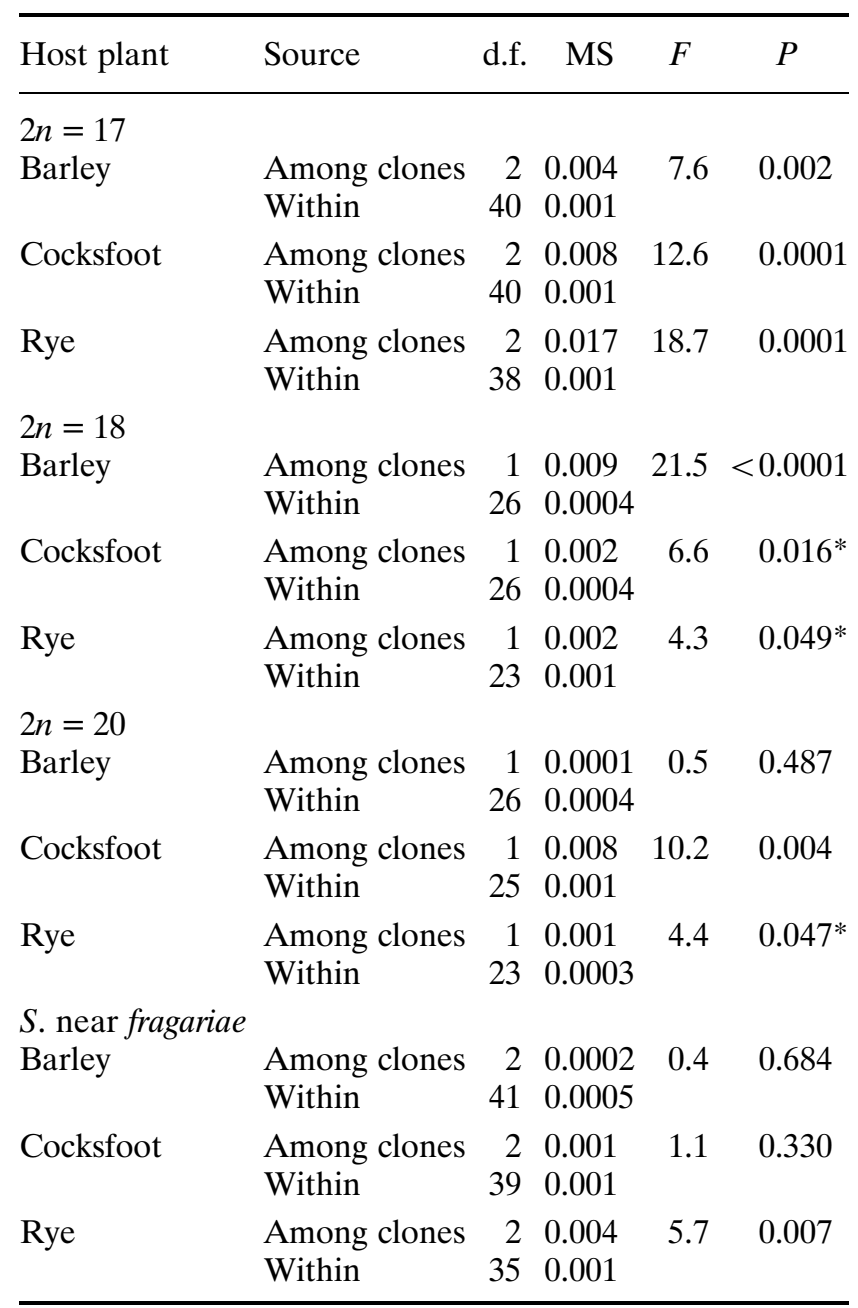

*Not significant at $P<0.05$ with sequential Bonferroni correction for 12 tests. by mutation and chromosomal rearrangement alone (Sunnucks et al., 1996). To put this into some context, note that these three races differ by between $63 \%$ and $88 \%$ of microsatellite alleles (figures which are changed little by the application of many more microsatellite loci; A. Wilson, unpubl. data). This level of difference is about that expected among full-siblings in a sexual species with heterozygosities similar to those seen in our data. Thus, the present differences detected between races $2 n=17$ and $2 n=20 / 2 n=21$ represent a rare demonstration of functional change arising rapidly in a free-living monophyletic apomictic (mitotic) lineage. Data such as these challenge assumptions that parthenogens will be very slow to respond to environmental change or to diversify into newly colonized habitats. (We will estimate the rate of divergence among races in terms of generations in future work.)

\section{Relationships of genotypical and phenotypical differences}

The responses to host plants must have a strong genetic component, because variance was very low among clone members but greater among clones and greatest among forms (Fig. 1; Tables 2 and 3). The results for barley will be least affected by environmental variation, because aphid stock cultures were maintained routinely for many generations on barley at the experimental temperature $\left(20^{\circ} \mathrm{C}\right)$, so these are focused on first. Genomic similarity was generally a good predictor of similarity in MRGR on barley. First, at the species level: $S$. near fragariae is a clear outlier in MRGR and is a sister species to $S$. miscanthi. Secondly, within-form: because most of the variance in MRGR of clones was explained by aphid form (species or chromosomal race) rather than by clone (Table 2; Fig. 1), it follows that genetic differences among clones of the same form have small effects on MRGR relative to the effect of genetic differences among forms. Thirdly, withinclone: members of a clone will be genetically identical except for very rare mutations and, accordingly, the variance in MRGR was small, probably caused mostly by environmental differences (Table 3 ). Among the four forms of $S$. miscanthi, the picture was more complicated. Races $2 n=20$ and $2 n=21$ are very closely related, and $2 n=17$ is a close sister group to these two, whereas $2 n=18$ is a distant sister to all of these. As predicted by high relatedness, the three clones comprising $2 n=20$ and $2 n=21$ did not have significantly different MRGR 
on barley (Fig. 1, $P>0.16$ ). However, $2 n=18$ or $2 n=17$ (or both) performed differently from expected: all three $2 n=17$ clones had significantly different MRGR on barley from both $2 n=20$ clones, whereas $2 n=18$ clone 80 did not react significantly differently from the $2 n=20$ clones (Fig. 1, $P>0.19)$. Although there are other possible explanations for the deviation of chromosomal races from expectation, the present data are consistent with a role of chromosomal rearrangements in differences in MRGR. There are also circumstantial reasons to think that the chromosomal rearrangements have important consequences in the field in these aphids. Although the $2 n=17 / 20 / 21$ group has diverged by mutation at several alleles at several loci and by chromosomal rearrangements, none of the many intermediate forms (carrying some changes but not others) has been found in large samples of freeliving aphids (Sunnucks et al., 1996 and further unpubl. data). Thus, it seems more than coincidental that the extant genotypes have different chromosomal arrangements. Chromosomal rearrangements are known to have important functional outcomes in other aphids (Hales et al., 1997).

\section{Other factors possibly affecting host relations}

Other factors that might be predicted to affect the response of aphids to host plants are time in culture (since collection in the field) and host plant at point of collection. Although the experiments were not designed to address these questions, it can be seen from Table 1 and Fig. 1 that these factors were unimportant predictors of response. For example,
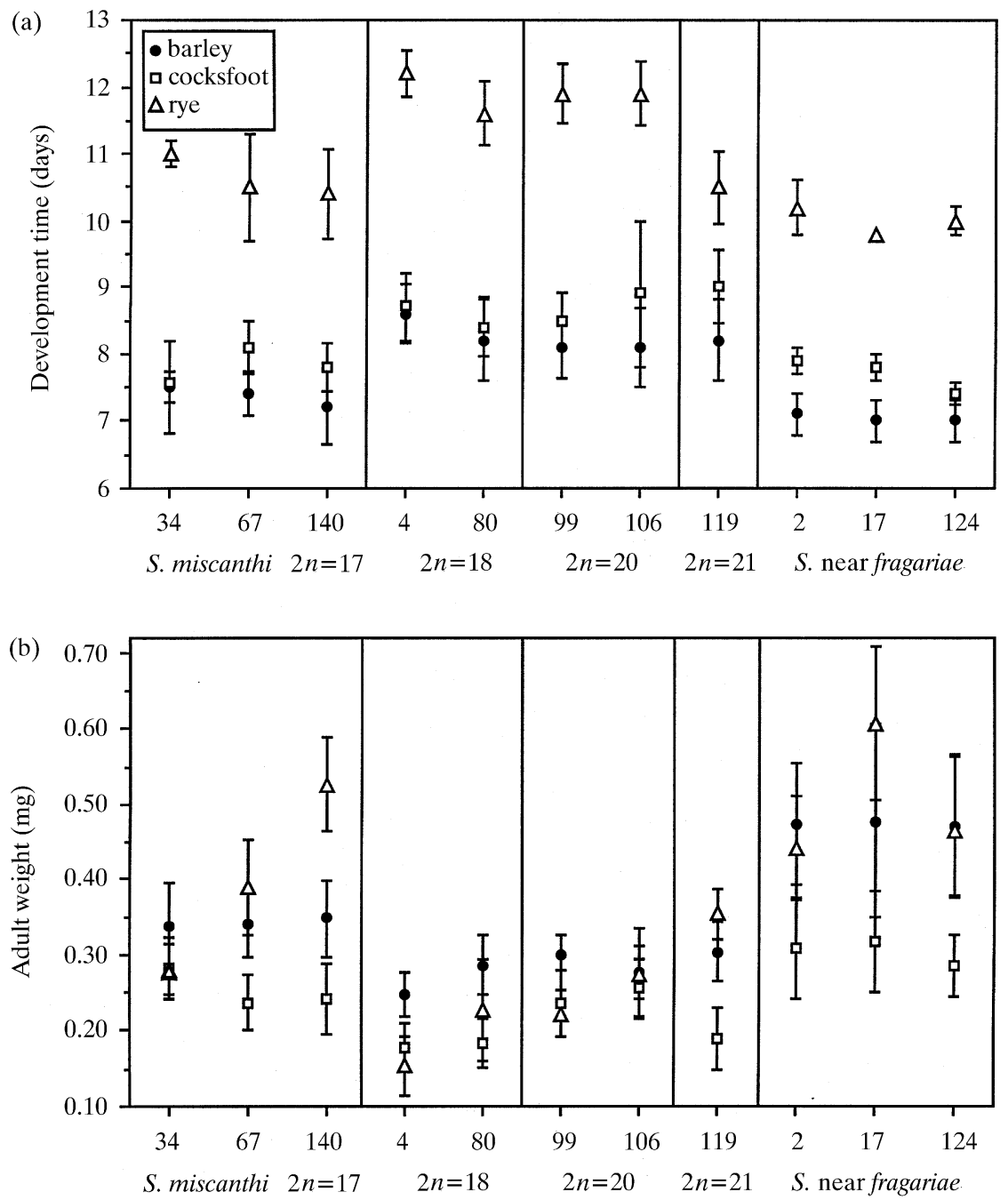

Fig. 2 Plots of growth variables for 11 Sitobion clones exposed to three different host treatments. (a) Time from birth to adult ecdysis (development time in days \pm SD). (b) Weight at adult ecdysis in $\mathrm{mg} \pm \mathrm{SD}$. 
within form $2 n=17$, clones 34 and 67 were collected in 1986, but their MRGR on barley bracket that of clone 140 collected in 1993. A similarly low effect of this factor is seen in the other forms. With respect to original host, six of the 11 clones were collected on Paspalum (all forms had at least one clone collected on this genus), one on Setaria, one on a sedge, one on 'cereal' and two 'unrecorded'. Only the last three could have been one of the test plants, and there are no obvious patterns indicating that aphids from any particular source host are associated with high or low MRGR on any test plant. For example, among $S$. near fragariae, one clone was collected on each of cereal, unrecorded and Paspalum, yet they have similar and nonsignificantly different MRGR on all hosts, except that clone 17 had higher MRGR on rye (Fig. 1; Table 3).

\section{Effects of different hosts and conditioning}

The above discussion was limited to results on barley, because there was no host shift involved in these data. Although the other hosts were less favourable, they generated qualitatively similar patterns of response in MRGR among the different aphids (Fig. 1). Aphids tested on cocksfoot and rye were the first of their clone to experience these plants (for at least four generations), and it is likely that some of their lower fitness on the new host was caused by host switching rather than by host characteristics per se (e.g. for S. avenae: De Barro et al., 1995b; conditioning is reviewed in Hales et al., 1997). Thus, the response of these aphids to exposure to an unfamiliar host plus any responses to the host itself were measured. This is relevant to the field situation because, as $S$. miscanthi and $S$. near fragariae in Australia are continuously parthenogenetic (Sunnucks et al., 1996) and a given grass species will flower for only part of a year (Wheeler et al., 1982), aphids frequently colonize hosts other than those used by previous generations. In addition, the effect of conditioning is itself likely to be under genetic control (e.g. De Barro et al., 1995b).

\section{Clone $\times$ host interactions and a model of clonal co-existence in the field}

Although responses to the hosts were generally correlated among clones (Fig. 1), significant clone $x$ host interactions existed, such that no clone within a form was generally a much better performer (high MRGR on one host was balanced by low MRGR on another). Such negative fitness correlations have been reported for other aphids, including $S$. avenae, and probably reflect trade-offs associated with resource specialization (Via, 1991; De Barro et al., 1995b; Sandström, 1996). Some clone $\times$ host interactions were large enough for a clone to outperform a clone of an otherwise faster growing form (Fig. 1). This would tend to allow the co-existence of different forms in the field, through fluctuating fitnesses in time and space (Via, 1991; Wilson \& Hebert, 1992). Under such a model, clones are expected to co-exist but oscillate in abundance over time and show degrees of specialization in various dimensions. We have detected such patterns of clonal diversity, change in abundance and specialization in field populations of a close relative of $S$. miscanthi, S. avenae (Sunnucks et al., 1997a). In the present experiments, the better performing forms on one host generally did better on all hosts (Fig. 1). The apparent contradiction between this situation and the evidence for trade-offs above may be solved by considering other factors in the ecology of these animals. A likely additional component of aphid fitness is ambient temperature and its interactions with other factors including host plant. We know that temperature is an important feature in the functional ecology of Australian Sitobion (Turak et al., 1998).

\section{Future directions}

Although we have provided evidence that a monophyletic parthenogenetic group showed genetically based trait variation concerning host plants, it will be very informative to investigate two further aspects of this system. First, the relevance of the host plant responses to the field situation needs to be assessed. The relevance of the present results is somewhat dependent on how MRGR translates into actual population growth under field conditions. Because two of our three treatments switch from 'familiar' to 'unfamiliar' host plants, it is possible that the correlation of MRGR with $r_{\mathrm{m}}$ would have been disturbed on these hosts, and the effect of low host plant quality could be progressive (tending to affect adults more). Thus, the present data might underestimate the variation in fitness arising from switches onto cocksfoot and rye. More importantly, it can be anticipated that many factors will interact with host relations (see above; and Hales et al., 1997). Secondly, ecological variation in these parthenogens should be compared with that in sexual relatives. We have not found sexually recombined 
genotypes of $S$. miscanthi or $S$. near fragariae in Australia (Sunnucks et al., 1996), but sexual morphs can be induced in the laboratory (Wilson et al., 1997), and breeding experiments are underway.

\section{Acknow ledgements}

We thank Lesley Hughes, Paul De Barro, Andrea Taylor, Steve Trewick, Jean-Christophe Simon, Seamus Ward, Tony Dixon, two anonymous reviewers and Terry Crawford for discussions and comments on the manuscript. Adrienne Nicotra, Saul Cunningham, David Warton, Mary Lam and Michael Dunlop provided advice on statistics. Thanks to Alex Wilson for unpublished data. This work was supported by ARC grant A19130882 to D.F.H. and by Macquarie University funds. Commonwealth Key Centre for Biodiversity and Bioresources Publication no. 208.

\section{References}

BLACKMAN, R. L. 1979. Stability and variation in aphid clonal lineages. Biol. J. Linn. Soc., 11, 259-277.

BLACKMAN, R. L. AND HALES, D. F. 1986. Behaviour of the $\mathrm{X}$ chromosomes during growth and maturation of parthenogenetic eggs of Amphorophora tuberculata (Homoptera, Aphididae), in relation to sex determination. Chromosoma, 94, 59-64.

CAILlAUd, C. M., DEDRYVER, C.-A., DI PIETRO, J. P., SIMON, J.-C., FIMA, F. AND CHAUBERT, B. 1995. Clonal variability in the response of Sitobion avenae (Homoptera: Aphididae) to resistant and susceptible wheat. Bull. ent. Res., 85, 189-195.

DE BARRo, P. J., SHERRATT, T. N., BROOKES, C. P., DAVID, O. AND MACLEAN, N. 1995a. Spatial and temporal genetic variation in British field populations of the grain aphid Sitobion avenae (F.) (Hemiptera: Aphididae) studied using RAPD-PCR. Proc. R. Soc. B, 262, 321-327.

DE BARRO, P. J., SHERRATT, T. N., DAVID, O. AND MACLEAN, N. 1995b. An investigation of the differential performance of clones of the aphid Sitobion avenae on two host species. Oecologia, 104, 379-385.

FAGERSTRÖM, T., BRISCOE, D. A. AND SUNNUCKS, P. 1998. Evolution in mitotic cell-lineages in multicellular organisms. Trends Ecol. Evol., 13, 117-120.

HALES, D. F., CHAPMAN, R. L., LARDNER, R. M., COWEN, R. AND TURAK, E. 1990. Aphids of the genus Sitobion occurring on grasses in southern Australia. J. Aust. ent. Soc., 29, 19-25.

HALES, D. F., TOMIUK, J., WÖHRMANN, K. AND SUNNUCKS, P. 1997. Evolutionary and genetic aspects of aphid biology: a review. Eur. J. Entomol., 94, 1-55.

Hughes, R. N. 1989. A Functional Biology of Clonal Animals. Chapman \& Hall, London.
JUDSON, O. P. AND NORMARK, B. 1996. Ancient asexual scandals. Trends Ecol. Evol., 1, 41-45.

LYNCH, M. 1984. Destabilizing hybridization, generalpurpose genotypes and geographic parthenogenesis. $Q$. Rev. Biol., 59, 257-290.

LYNCH, M. 1985. Spontaneous mutations for life-history characters in an obligate parthenogen. Evolution, 39, 804-818.

LYNCH, M., BURGER, R., BUTCHER, D. AND GABRIEL, W. 1993. The mutational meltdown in asexual populations. J. Hered., 84, 339-344.

MAYNARD Smith, J. 1978. The Evolution of Sex. Cambridge University Press, Cambridge.

MÜllER, J. AND SEITZ, A. 1995. Differences in genetic structure and ecological diversity between parental forms and hybrids in a Daphnia species complex. Hydrobiologia, 307, 25-32.

RICE, W. R. 1989. Analyzing tables of statistical tests. Evolution, 43, 223-225.

SANDSTRÖM, J. 1996. Temporal changes in host adaptation in the pea aphid Acyrthosiphon pisum. Ecol. Entomol., 21, 56-62.

SIMON, J.-C., CARREL, E., HEBERT, P. D. N., DEDRYVER, C.-A., BONHOMME, J. AND LE GALLIC, J.-F. 1996a. Genetic diversity and mode of reproduction in French populations of the aphid, Rhopalosiphum padi (L.). Heredity, 76, 305-313.

SiMON, J.-C., MARTINEZ-TORRES, D., LATORRE, A., MOYA, A. AND HEBERT, P. D. N. 1996b. Molecular characterization of cyclic and obligate parthenogens in the aphid Rhophalosiphum padi (L.). Proc. R. Soc. B., 263, 481-486.

SUNNUCKS, P. AND HALES, D. F. 1996. Numerous transposed sequences of mitochondrial cytochrome oxidase I-II in aphids of the genus Sitobion (Hemiptera: Aphididae). Mol. Biol. Evol., 13, 510-523.

SUNNUCKS, P., ENGLAND, P. E., TAYLOR, A. C. AND HALES, D. F. 1996. Microsatellite and chromosome evolution of parthenogenetic Sitobion aphids in Australia. Genetics, 144, 747-756.

SUNNUCKS, P., DE BARRO, P. J., LUSHAI, G., MACLEAN, N. AND HALES, D. F. 1997a. Genetic structure of an aphid studied using microsatellites: cyclic parthenogenesis, differentiated lineages, and host specialization. Mol. Ecol., 6, 1059-1073.

SUNNUCKS, P., DRIVER, F., BROWN, W. V., CARVER, M., HALES, D. F. AND MILNE, W. M. 1997b. Biological and genetic characterization of morphologically similar Therioaphis trifolii (Monell) (Hemiptera: Aphididae) with different host utilization. Bull. ent. Res., 87, $425-436$.

TOLINE, C. A. AND LYNCH, M. 1994. Mutational divergence of life-history traits in an obligate parthenogen. Genome, 37, 33-35.

TURAK, E., SUNNUCKS, P. AND HALES, D. F. 1998. Different responses to temperature in three closely-related parthenogenetic cereal aphids. Entomologia exp. appl., 86, 49-58.

(c) The Genetical Society of Great Britain, Heredity, 81, 638-647. 
UNDERWOOD, A. J. 1997. Experiments in Ecology: Their Logical Design and Interpretation Using Analysis of Variance. Cambridge University Press, Cambridge.

VIA, s. 1991. Specialized host plant performance of pea aphid clones is not altered by experience. Ecology, 72, 1420-1427.

WHEELER, D. J. B., JACOBS, S. W. L. AND NORTON, B. E. 1982. Grasses of New South Wales. University of New England
Monographs 3. Armidale, N.S.W.

WILSON, A. C. C., SUNNUCKS, P. AND HALES, D. F. 1997. A microsatellite linked to the X-chromosome of Sitobion aphids reveals random inheritance of the X-chromosome in males. Genet. Res., 69, 233-236.

WILSON, C. C. AND HEBERT, P. D. N. 1992. The maintenance of taxon diversity in an asexual assemblage: an experimental analysis. Ecology, 73, 1462-1472. 